\section{RESURRECTING A DYING TRADITION: THE STRATEGIC MANAGEMENT OF TRADITIONAL THAI DESSERTS AND SNACKS AT LAAN FUENG NAKORN, THE OLD SIAM PLAZA}

\author{
Tanachanan Petchsombat ${ }^{1}$
}

\begin{abstract}
The ineluctable force of globalization is having an immense impact on local traditions worldwide. Thai cultures, and lifestyles have also received the full brunt of these 'nouvelle' invasions. Old traditions, including food prepared according to century-old recipes, have started to disappear. The number of venues selling such traditional Thai desserts and snacks has shrunk to only an astonishing few. To halt the death of this legacy, the management of those shops must conduct a study to ascertain what influences customers to come buy these traditional products and to incorporate the findings into their management strategy. In the end, this study revealed quite unexpected outcomes as to why people chose to buy one product but not another.
\end{abstract}

\footnotetext{
1 Master of Arts in Cultural Management, Graduate School, Chulalongkorn University, Bangkok.
}

\section{Introduction}

This study was inspired by the fact that traditional Thai desserts and snacks, our heritage since the Sukhothai era, have gradually had their significance in our national culture eroded by a continuous barrage of the more trendy foreign food products. Phunwarat Entertainment Co., Ltd., (hereinafter "Phunwarat Entertainment") has managed traditional Thai desserts and snacks at Laan Fueng Nakorn in The Old Siam Plaza for over a decade, but is now facing this cultural divergence. "The Strategic Management of Traditional Thai Desserts and Snacks at Laan Fueng Nakom, The Old Siam Plaza" was, hence, conceived to study the outcomes of such cultural-behavioral impacts, for instance: management schemes; the views of vendors on the management; customers' satisfaction in terms of product, price, place, and promotion; and the effectiveness of the marketing tools, such as cultural demonstration, on the sales of traditional desserts and snacks at this venue.

The Eclectic Approach on-site study involved a combination of observations, indepth interviews, and questionnaires. The researcher carried out these surveys from June through August in 2004, and also used 
the theory of strategic management process as outlined in 'Key Functional Tactics in Marketing Strategy' (Pearce and Robinson, 2000: 12-15) to analyze the information gathered from these in-depth interviews. Data analysis collected from questionnaires utilized mean and percentages as well as triangulation.

\section{Traditional Thai Desserts and Snacks}

Traditional Thai desserts and snacks have been with the people of this Kingdom since the Sukhothai era. The origin of these cultural products in the form of epicurean delights traces back to the Ayutthaya period. Marie Pina de Guimar, wife of Constantine Falcon, minister under King Narai the Great, brought some well-known traditional Thai desserts, such as thongyib 'pinched gold', thongyod 'golden drop', and foithong 'golden thread', to Thailand from Portugal. Later, the court granted her a Thai title, Thao Thong Keebmaa. S he u sed h er P ortuguese recipes, which relied heavily on egg yolks and sugar syrup, and combined them with local Thai ingredients, such as palm sugar, coconut milk, and flour, to create new and unique desserts (Sansanee \& Pramin, 2003: 61-67).

After the Ayutthaya period, King Rama II of the Rattanakosin era (1809-1824) immortalized Thai food and desserts in his poetic work entitled "Poem of Food and Desserts" or, in Thai, "Karp Heh Chom Krueng Kao Waan" (Lek, 2000). According to Thai historical tradition, Thai desserts were first served to the Royal Family but later gained in popularity and became food for everyone. Then, they came to play a role in religious ceremonies and celebrations in all aspects of Thai society, such as weddings, Songkran Festival (the traditional Thai New Year), and ordination ceremonies (Kuna, 1999: 6).

Unfortunately, the heritage of traditional Thai desserts and snacks is slowly disappearing from modern Thai society. Because of radical changes in their lifestyles, only a few of the younger Thai generation consume traditional Thai desserts and snacks. Traditional forms and norms of behavior are breaking down, buffeted by an array of internal and external forces (Klausner, 1998: 77). For this reason, traditional Thai desserts and snacks are not popular in today's changing society. Cakes and potato chips quickly replaced khanom mohkaeng and tongmuan. The country's unique cuisine began its nosedive into the abyss.

The Old Siam Plaza realized that traditional Thai arts and culture may disappear because of the influence of western culture. Therefore, they assigned Phunwarat Entertainment to create cultural activities at Laan Fueng Nakorn to promote and preserve traditional ways of life and the Thai culinary heritage. Since its opened in 1993, Laan Fueng Nakorn has become a famous venue in Bangkok for selling authentic traditional Thai desserts and snacks. It dedicated itself to selling a variety of Thai desserts and snacks, such as pansip, ja monkut, khaokreap-pakmoh, and miangkhum, which have become difficult to find in the modern-day market (Rangsima, 1993)

The problem for this study is that Phunwarat Entertainment had been successful for more than ten years in initiating strategies to sell Thai desserts and snacks at Laan Fueng Nakorn. But times have changed, and the old marketing concepts no longer work as they once did. Therefore, the company needs to find a new 
existing one, so that it can hold and ultimately expand the target market for traditional desserts and snacks in Thai society.

This study aims to explore the management strategy that Phunwarat Entertainment has used to manage these desserts and snacks products, as well as the vendors at Laan Fueng Nakorn, focusing in detail on the following:

1. study the strategic management concepts $P$ hunwarat Entertainment Co., Ltd., used to manage traditional Thai desserts and snacks at Laan Fueng Nakorn;

2. check the perspective of vendors towards the management of Laan
3. evaluate customer satisfaction with the management strategy in terms of the ' 4 Ps';

4. assess effectiveness of the marketing tools, such as cultural demonstration.

The research findings may be summarized as follow:

1. Phunwarat Entertainment used functional tactics in its management theory based on marketing, financial, production, and human resource strategies.

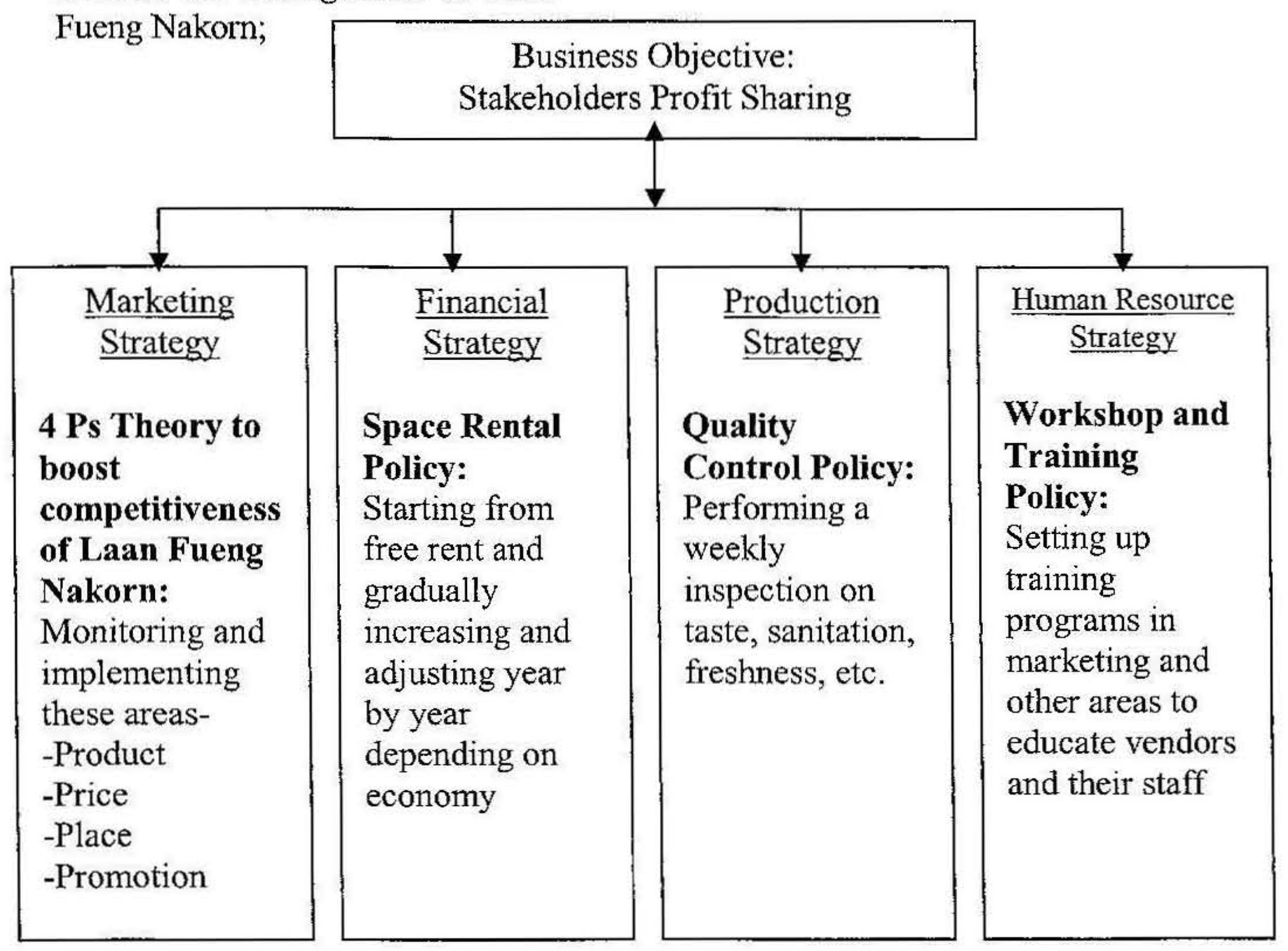

Figure 1: Business strategy of Laan Fueng Nakorn based on functional tactics on its objectives 
In accordance with Strategic Management Theory, this research mainly focuses on the functional tactics scheme. The strategic management practice Phunwarat Entertainment used for managing Laan Fung Nakorn can be described as follows:

\section{Marketing Strategy}

Mr. Kitisak Napahunwarat, the Managing Director of Phunwarat Entertainment planned a marketing strategy for Laan Fueng

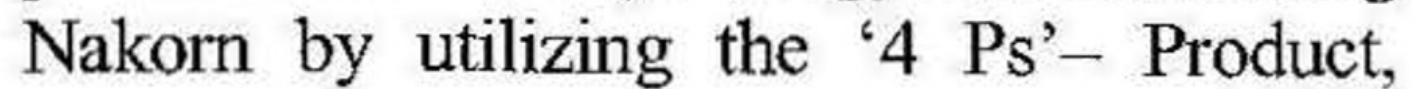
Price, Place, and Promotion-as strategic tools to market and manage dessert and snack products.

\section{Product Management Strategy}

Phunwarat Entertainment set the selection process for dessert and snack products to sell at Laan Fueng Nakorn as a key task. The products needed to be in traditional style, and supportive of the concept of The Old Siam Plaza as a venue for both marketing and preserving traditional Thai artistic and cultural products. Therefore, Phunwarat Entertainment devised four criteria for selecting both the dessert and snack products and the vendors, as follows:

\section{Taste of Food}

It is imperative that the desserts and snacks taste delicious, using traditional recipes, styles, and processes. Likewise, the utensils should be in the traditional style. For these reasons, the marketing staff of Phunwarat Entertainment searched for suitable vendors by considering only those with superior reputations for a particular kind of traditional desserts and snacks regardless of where the vendors were based, whether in a market or on the street. The staff taste- tested the desserts and snacks of many vendors and selected only the best ones to sell at Laan Fueng Nakorn.

\section{Hygiene}

In addition to good taste, the vendors should prepare and package the desserts and snacks hygienically. Above all, the products must be safe for the customers' health.

\section{Natural Ingredients}

The ingredients of desserts and snacks rely on natural products. For example, the yellow color of Khaokreap-pakmoh comes from pumpkins.

\section{Image of the Sellers}

The image of the sellers should harmonize with the products. Vendors should look clean and attractive, wearing Thai costumes. They need to be service-minded and exhibit a welcoming manner towards customers. For instance, the khanom bueng vendor selected to sell at Laan Fueng Nakorn, had to change her costumes to the traditional Thai style, and replace her flipflops with cut shoes.

\section{Price Management Strategy}

From the beginning, desserts and snacks at Laan Fueng Nakorn adopted street prices with a minimum price tag set at ten baht per item. Mr. Kitisak used this pricing strategy to manage the sales of desserts and snacks by competing with street vendors in the area. The advantage of his venue, its location, and its competitive prices drew in many customers. Therefore, this price management strategy was appropriately 
deployed and deemed useful to serve the needs of Laan Fueng Nakorn.

\section{Place Management Strategy}

During the first run of selling desserts and snacks at Laan Fueng Nakorn, the vendors had to rotate the locations of their shops every six months due to the benefit-sharing policy established by the management company. Some shops may not have been in a good location for customers to see their products, like the shops near the walkway. Phunwarat Entertainment was concerned that every shop should have the same opportunity to sell their products; hence, the rotation policy. However, the shop rotation policy was terminated after customers became familiar with products, shop layout, and location.

The management of Laan Fueng Nakorn used the strategy of channel distribution as criteria to rotate the shops as a mean of benefit-sharing. Also, the contemporary Thai architectural style of Laan Fueng Nakorn in The Old Siam Plaza created the ambience of a dessert-and-snack village in harmony with its objective. In addition, the management company also enhanced the image of Laan Fueng Nakorn by insisting on a traditional Thai atmosphere, by having staff wear Thai costumes, and by maintaining the cleanliness of the shops. These strategies were aimed to keep the unique image of Laan Fueng Nakorn.

\section{Promotion Management Strategy}

Phunwarat Entertainment used the promotion management strategy as a marketing tool to sell traditional dessert and snack products at Laan Fueng Nakorn. The company created promotional activities to help vendors sell their products and expand their market channels. For example, they held a traditional dessert-and-snack festival during Songkran Festival (Thai New Year celebration), April 13-15, and another on the Queen's Birthday, August 12, each year. In addition, they held a Traditional Thai Costume Fancy Contest one year at Laan Fueng Nakorn in a Thai atmosphere replete with classical Thai music performances. The vendors carried desserts and snacks in old-style balancing baskets and circulated around the plaza. The most recent major sales promotion took place in 2003 , to celebrate the ten-year anniversary of The Old Siam Plaza, during which customers spending more than 200 baht would receive premiums.

Phunwarat Entertainment also showed vendors how to package their products as suitable gifts for the holiday and New Year's seasons. For instance, vendors packaged thongyip and thongyod in small boats, ceramic plates, or beautiful rattan baskets. Furthermore, Phunwarat Entertainment urged shop vendors to create their own sales-promotion activities and to launch them at any time conducive to making a profit, such as a "buy one get one free" sales pitches.

The company used the media to publicize Laan Fueng Nakom. They arranged for television spots on domestic and international channels, such as on the cooking programs of channels $3,5,7,9,11$, and ITV in Thailand, NHK in Japan, and local channels in Korea, and also magazine reviews, especially in tourist publications. For instance, Sawasdee Magazine, the inflight magazine of Thai Airways International, listed traditional desserts and snacks at The Old Siam Plaza in the article "99 Cool Things about Bangkok" as a place tourists needed to know and visit (Gampell et al, 2003: 46). 
Phunwarat Entertainment used this promotion management strategy to attract more customers to Laan Fueng Nakorn, to help vendors boost their sales by setting up special events and gimmickry, and to use a variety of media such as television, magazines, and newspapers to propagate the image of Laan Fueng Nakorn as a hub for traditional Thai d esserts a nd s nacks in Bangkok.

\section{Financial Management Strategy}

Initially, the Laan Fueng Nakom project was a one-time event: a demonstration to the public and media of the traditional ways of cooking Thai desserts during the grandopening celebration of The Old Siam Plaza. At the time, the Plaza's management paid vendors to cook in front of the public and invited guests to taste the products. The event turned out to be such a success that the Old Siam Plaza asked Phunwarat Entertainment to continue the Laan Fueng Nakorn tradition by subleasing certain spaces out to selected vendors using a profit-sharing system.

In 1994, selected vendors were able to sell their products at Laan Fueng Nakom without paying any rent. In 1995, Phunwarat Entertainment started to collect rent from vendors equal to $10 \%$ of gross sales per month. In 1996, they increased the monthly rent to a maximum of 2,500 baht per booth because, by that time, the vendors were generating steady income and starting to make profit. After three more years, The Old Siam Plaza had become a popular venue for customers who liked to purchase traditional desserts and snacks, and thereafter, the rent was rose slowly in multiple stages from 2,500 baht to the current 20,000 baht per booth per month. The vendors have been satisfied with the profit-sharing policy that Phunwarat
Entertainment and The Old Siam Plaza initiated. Evidence of its success is the fact that many of the vendors have been at Laan Fueng Nakorn continuously for the past 11 years since opening day and that the booths are $100 \%$ occupied and even have a long waiting list.

\section{Production Management Strategy}

Fresh, delicious, and hygienic was the standard of quality that Phunwarat Entertainment required of vendors for the desserts and snacks at Laan Fueng Nakorn. The company mounted a tasting team to sample the food and check for quality, and at the same time they monitored the cleanliness and decoration of the booths and the traditional dress wom by the sellers. Occasionally, Phunwarat Entertainment invited experts to sample the food and compare it with similar items produced elsewhere, as part of its quality-control efforts. Food tasting and other qualitycontrol methods took place daily during the initial stages of the project; later, once a month, and now, approximately quarterly, depending on timing and marketing conditions.

However, the tasting results from its staff and the experts may not have accurately reflected the broader market; therefore, the vendors needed to do marketing research and directly observe consumers' behavior. This research sometimes resulted in adjustments being made to the mix of ingredients because, for example, today's consumers are more health conscious than in the past. Today, for instance, many customers refrain from buying foods that are too sweet, a decided change from the past. To maintain economic success, the vendors came to realize that they needed to adjust to contemporary market trends 
while at the same time preserving the traditional elements of their recipes.

The management of Laan Fueng Nakorn went all out to find the best vendors for preparing food to sell to their customers. These vendors produce tasty desserts and snacks from the finest and freshest ingredients. With their accrued knowledge and experience, they are able to provide "just in time" inventory to guarantee the best-possible food quality and to ensure timely delivery to the customers daily.

\section{Human Resource Management Strategy}

Phunwarat Entertainment managed its human resources, i.e., staff, vendors, and employees, by providing them with marketing knowledge through the organization of seminars and training programs built around the "4 Ps" basic marketing theory. Most of the vendors were ordinary street hawkers, who did not quite know how to implement the sales, let alone the marketing principles and theories. In the seminars, the marketing instructor helped them to better understand their products, prices, venues, and promotional schemes, so that these vendors could apply the " 4 Ps" principles to increase their profitability. The vendors' employees also underwent training to serve the customers better, which was very important because these shop assistants had direct contact with the customers and would know what the customers really wanted. Unfortunately, this training program, while having some positive effects, suffered from a high employee turnover rate, thus limiting its usefulness.

Realizing the problem of high employee turnover, the management later deployed the human-resource management strategy to find ways for the vendors to strike a better deal with their employees, to make them feel a part of the family, and to make them feel competent and valued. In the long run, the management definitely gains more, by investing in improving the potential of these vendors and their employees. These people will help to build the value and fame of Laan Fueng Nakom, securing its role as the traditional Thai desserts and snacks center of Bangkok.

2. The vendors were highly satisfied with the management of Laan Fueng Nakorn in terms of the following:

\section{Marketing Management Strategy}

Vendors were able to manage their own shops by following the management policy. Even though there are more than 100 kinds of products sold at Laan Fueng Nakom, the management has not allowed any duplicate products. Thus, the vendors have been happy there because their products are unique in the venue.

\section{Financial Management Strategy}

Of six vendors interviewed at Laan Fueng Nakorn except for the newest vendor, all five long-time vendors were quite satisfied with the space rental policy. They paid what they deemed fair and felt that they grew together as one business entity. New vendors started to rent the space in 2003, when the price was already high. Knowing that these vendors might have to face some financial difficulties, the management told them to adjust their food prices accordingly but reasonably. 


\section{Production Management Strategy}

Vendors were meticulous in producing their products. They took pride in the quality and taste of their homemade products.

\section{Human Resource Management Strategy}

The management has arranged marketing seminars for vendors and staff on topics such as how to deal with customers, how to package products, and how to promote products. In the last two years, they stopped holding marketing seminars for some reasons, but the vendors would prefer the management to reinstate the seminars again if possible.

3. Customer satisfaction in the four areas as follows:

\section{Product Management}

The customers were most satisfied with the taste of the products. The variety, hygiene, freshness, natural ingredients, appearance and craftsmanship were more or less at satisfactory levels. Unfortunately, the packaging and the novelty of the products less impressed them.

\begin{tabular}{|l|c|c|c|}
\hline \multicolumn{1}{|c|}{ Various Aspects of products } & Management & Vendors & Customers \\
\hline Variety and Choices & $* * *$ & $* *$ & $* *$ \\
\hline Taste & $* * *$ & $* * *$ & $* * *$ \\
\hline Sanitary and Cleanliness & $* * *$ & $* * *$ & $* *$ \\
\hline Freshness & $* * *$ & $* * *$ & $* *$ \\
\hline Natural Ingredients & $* * *$ & $* *$ & $* *$ \\
\hline Package & $* * *$ & $* *$ & $*$ \\
\hline Cooking Demonstration & $* * *$ & $* * *$ & $*$ \\
\hline Appearance and Looks & $* * *$ & $* *$ & $* *$ \\
\hline Quality of Product/Craftsmanship & $* * *$ & $* *$ & $* *$ \\
\hline Product Novelty & $* * *$ & $* *$ & $*$ \\
\hline
\end{tabular}

Figure 2: Triangulation significance on various aspects of product

$* * * \quad=$ Most Important (over 90 percent)

$* * \quad=$ Very Important $(80-89$ percent $)$

* $\quad=$ Somewhat Important (below 80 percent) 


\section{Price Management}

The customers were most $\mathrm{s}$ atisfied $\mathrm{w}$ ith the price compared to the quality of the products. However when compared to the standard market price, they were less happy. The figure below shows how customers feel about prices in various aspects compared with outside competitors.

\begin{tabular}{|c|c|c|c|}
\hline Level of Satisfaction & Management & Vendors & Customers \\
\hline Price vs. Quality of Product & $* * *$ & $* * *$ & $*$ \\
\hline Price vs. Quantity of Product & $* * *$ & $* * *$ & $*$ \\
\hline Price vs. Market Price & $* * *$ & $* * *$ & $*$ \\
\hline
\end{tabular}

Figure 3: Triangulation satisfaction on various aspects of price

$$
\begin{array}{ll}
* * * & =\text { Most Satisfied (over } 90 \text { percent) } \\
* * & =\text { Very Satisfied }(80-89 \text { percent) } \\
* & =\text { Somewhat Satisfied (below } 80 \text { percent) }
\end{array}
$$

\section{Place Management}

The customers were most attracted to the traditional Thai setting and the shops' cleanliness. There is still room for improvement in areas such as decoration, service, amenities, and security. The shop assistants wearing Thai costumes did not impress these customers as much as previously. The location is difficult to access and thus ranked quite low with the customers and the vendors alike; unfortunately, it is beyond the management's capacity to change this. They should, therefore, concentrate their efforts on improving the manageable criteria.

\begin{tabular}{|l|c|c|c|}
\hline \multicolumn{1}{|c|}{ Level of Satisfaction } & Management & Vendors & Customers \\
\hline Cleanliness & $* * *$ & $* * *$ & $* *$ \\
\hline Decoration & $* * *$ & $* * *$ & $*$ \\
\hline Service & $* * *$ & $* * *$ & $*$ \\
\hline Traditional Thai- Setting & $* * *$ & $* * *$ & $* *$ \\
\hline Shop Assistants in Thai Costumes & $* * *$ & $* * *$ & $*$ \\
\hline Other Amenities & $* * *$ & $* *$ & $*$ \\
\hline Security & $* * *$ & $* * *$ & $*$ \\
\hline Location & $* * *$ & $*$ & \\
\hline
\end{tabular}

Figure 4: Triangulation significance on various aspects of place 


$$
\begin{array}{ll}
* * * & =\text { Most Satisfied (over } 90 \text { percent) } \\
* * & =\text { Very Satisfied }(80-89 \text { percent) } \\
* & =\text { Somewhat Satisfied (below } 80 \text { percent) }
\end{array}
$$

\section{Promotion Management}

The customers liked the festive gift baskets the vendors offered them during the promotion period. They were also drawn to the special activities during New Year, Songkran, and The Old Siam Plaza $10^{\text {th }}$ Anniversary.

\begin{tabular}{|l|c|c|c|}
\hline \multicolumn{1}{|c|}{ Level of Importance } & Management & Vendors & Customers \\
\hline $\begin{array}{l}\text { Creating Traditional Thai } \\
\text { Atmosphere }\end{array}$ & $* * *$ & $* * *$ & $*$ \\
\hline Discount & $* * *$ & $* * *$ & $*$ \\
\hline Other Promotion Incentives & $* * *$ & $* * *$ & $*$ \\
\hline Festive Gift Baskets & $* * *$ & $* * *$ & $* *$ \\
\hline Novelty Festive Gift Baskets & $* * *$ & $* *$ & $*$ \\
\hline
\end{tabular}

Figure 5: Triangulation Significance on various aspects of past promotion

*** $\quad=$ Most Important (over 90 percent)

** $\quad=$ Very Important ( $80-89$ percent $)$

* $\quad=$ Somewhat Important (below 80 percent)

Nevertheless, for future promotional events to be planned at Laan Fueng Nakorn, the management should place more focus on the novelty of the festive gift baskets. The customers liked these gift baskets in the past, but they want something new and creative for the next special event. This means that when they come to shop here, they want to purchase goods to give to their loved ones which can be put in something fresh and eye-catching, instead of the conventional wrapping. The management may even advertise Laan Fueng Nakorn on the package so that, when carried around, people who come across it will be attracted to it and want to buy it, too. 


\begin{tabular}{|l|c|c|c|}
\hline \multicolumn{1}{|c|}{ Level of Importance } & Management & Vendors & Customers \\
\hline $\begin{array}{l}\text { Creating Traditional Thai } \\
\text { Atmosphere }\end{array}$ & $* * *$ & $* * *$ & $*$ \\
\hline Discount & $* * *$ & $* * *$ & $*$ \\
\hline Other Promotion Incentives & $* * *$ & $* * *$ & $*$ \\
\hline Festive Gift Baskets & $* * *$ & $* * *$ & $*$ \\
\hline Novelty Festive Gift Baskets & $* * *$ & $* *$ & $* *$ \\
\hline
\end{tabular}

Figure 6: Triangulation significance on various aspects of future promotion

*** $\quad=$ Most Important (over 90 percent)

$* * \quad=$ Very Important (80-89 percent)

* $\quad=$ Somewhat Important (below 80 percent)

4. The effectiveness of marketing tools such as cultural demonstration on the sales of traditional products fared well, based on customers' responses. These on-site demonstrations increased the sales of traditional Thai desserts and snacks at Laan Fueng Nakorn because they not only enhanced the visual atmosphere of the place but also enticed customers with the sweet aroma of the freshly cooked products.

\begin{tabular}{|c|c|c|c|}
\hline Level of Importance & Management & Vendors & Customers \\
\hline Influence of Traditional Thai Setting & $* * *$ & $* * *$ & $* *$ \\
\hline
\end{tabular}

Figure 7: Triangulation significance on Thai setting

*** $\quad=$ Most Important (over 90 percent)

$* * \quad=$ Very Important ( $80-89$ percent $)$

* $\quad=$ Somewhat Important (below 80 percent)

\section{RECOMMENDATION AND CONCLUSION}

The many factors that customers indicated to have influenced their shopping behaviors at Laan Fueng Nakorn are depicted in the figure below. 